\title{
Expression of atrial-fetal light chains in cultured human cardiomyocytes after chemical ischemia-reperfusion injury
}

\author{
MARTA BANASZKIEWICZ, AGNIESZKA OLEJNIK, ANNA KRZYWONOS-ZAWADZKA, \\ KORNELA HAŁUCHA and IWONA BIL-LULA
}

\begin{abstract}
Division of Clinical Chemistry and Laboratory Haematology, Department of Medical Laboratory Diagnostics, Faculty of Pharmacy, Wroclaw Medical University, 50-556 Wroclaw, Poland
\end{abstract}

Received May 7, 2021; Accepted July 19, 2021

DOI: $10.3892 / \mathrm{mmr} .2021 .12410$

\begin{abstract}
Atrial light chains (ALC1) are naturally present in adult heart atria, while ventricular light chains (VLC1) are predominant in ventricles. Degradation of VLC1 and re-expression of ALC1 in heart ventricles are associated with heart disorders in response to pressure overload. The aim of the current study was to investigate changes in myosin light chain expression after simulated ischemia and simulated reperfusion (sI/sR). Human cardiomyocytes (HCM) isolated from adult heart ventricles were subjected to chemical ischemia. The control group was maintained under aerobic conditions. Myocyte injury was determined by testing lactate dehydrogenase (LDH) activity. The gene expression of ALC1, VLC1 and MMP-2 were assessed by reverse transcription-quatitive PCR. Additionally, protein synthesis was measured using ELISA kits and MMP-2 activity was measured by zymography. The results revealed that LDH activity was increased in sI/sR cell-conditioned medium $(\mathrm{P}=0.02)$, confirming the ischemic damage of HCM. ALC1 gene expression and content in HCM were also increased in the sI/sR group $(\mathrm{P}=0.03$ and $\mathrm{P}<0.001$, respectively), while VLC1 gene expression after $\mathrm{sI} / \mathrm{sR}$ was decreased $(\mathrm{P}=0.008)$. Furthermore, MMP-2 gene expression and synthesis were lower in the sI/sR group when compared with the aerobic control group $(\mathrm{P}<0.001$ and $\mathrm{P}=0.03$, respectively). MMP-2 activity was also increased in $\mathrm{sI} / \mathrm{sR}$ cell-conditioned medium $(\mathrm{P}=0.006)$. In conclusion, $\mathrm{sI} / \mathrm{sR}$ treatment led to increased ALC1 and decreased VLC1 expression in ventricular cardiomyocytes, which may constitute an adaptive mechanism to altered conditions and contribute to the improvement of heart function.
\end{abstract}

Correspondence to: Dr Iwona Bil-Lula, Division of Clinical Chemistry and Laboratory Haematology, Department of Medical Laboratory Diagnostics, Faculty of Pharmacy, Wroclaw Medical University, Borowska 211A Street, 50-556 Wroclaw, Poland E-mail: iwona.bil-lula@umed.wroc.pl

Key words: atrial myosin light chains, injury, ischemia, reperfusion, ventricular myosin light chains

\section{Introduction}

Myosin is composed of two heavy chains (MHC) and two pairs of light chains: essential (non-phosphorylatable) light chain 1 (MLC1) and regulatory (phosphorylatable) light chain 2 (MLC2) (1-6). MLC2 are indirectly responsible for modulating adenosine triphosphatase activity of MHC (7-11), while the main function of MLC1 is to stabilize the MHC head region where actin and ATP binding sites are located $(4,5,12,13)$. At least two types of alkali essential myosin light chains 1 are distinguished in an adult human heart. There are atrial and ventricular myosin light chains (ALC1 and VLC1, respectively) (12,14-19). In fetal stage, fetal light chains 1 (FLC1) are present in the human heart ventricles. This form is identical to ALC1, hence also called atrial-fetal light chain $1(1,5,7,19)$. After birth, the expression of FLC1 rapidly decreases in the ventricles and VLC1 plays the main contractile role $(13,20)$. There are several reports showing that the expression of ALC1 in ventricles increases with the occurrence of congenital heart diseases such as tetralogy of Fallot, valvular heart defects or hypertrophic cardiomyopathy $(1,13,16-18,21)$. ALC1 may also appear in the heart ventricles of the adults suffering from heart failure and in response to pressure overload $(16,22)$.

Direct contractile machinery damage and degradation of sarcomeres during oxidative stress leads to disturbance of the balance between synthesis and degradation of contractile proteins $(19,23,24)$. It has also been documented that oxidative stress induces post-translational modifications: nitration, nitrosylation and phosphorylation of MLC1 and MLC2 increasing their affinity to the proteolytic enzymes $(4,14,15,25-27)$. Among the main contributors to ischemia-reperfusion (I/R) injury of the heart are enhanced production of reactive oxygen species, expression of nitric oxide synthase and overproduction of nitric oxide, which subsequently lead to increased matrix metalloproteinase-2 (MMP-2) activity (28-32). Therefore, MLC become more susceptible to degradation by MMP-2 $(4,18)$. As a consequence, expression of the atrial light chain 1 gene (MYL4 gene), encoding ALC1 and subsequent synthesis of this protein was observed $(13,33,34)$.

Data showed that the contractile apparatus with myosin containing ALC1 is characterized by a faster cross-bridge kinetics, an increase in maximal shortening velocity, rate of 
tension development, isometric force generation, duty ratio and higher calcium sensitivity of force generation $(1,3,6,12,14)$. This effect results from weaker binding of myosin and ALC1 to actin compared to myosin and VLC1 $(21,35,36)$. ALC1 is shorter than VLC1, hence it imposes a weaker 'molecular load' on the cross-bridge (37). The amount of interactions between myosin containing ALC1 and actin may be reduced. It results in an increase in kinetics and force generation, which causes an increase in shortening speed and an improvement in the state of contractility $(38,39)$.

Taking the above into account, the main aim of this research was to explore, whether the expression of ALC1 is increased in the simulated ischemia/reperfusion (sI/sR) injury model of cardiomyocytes isolated from adult heart ventricles in comparison to the cardiomyocytes subjected to aerobic conditions. The next important objective was to examine the MMP-2 changes in the above mentioned sI/sR model. We explored changes in gene expression and concentration of ALC1 and VLC1 in human cardiac myocytes (HCM). We also performed indirect immunofluorescence staining to visualize the differences between ALC1 and VLC1 cell expression. We measured lactate dehydrogenase (LDH) activity as a marker of cell injury and MMP-2 gene expression, content and activity as an indicator of oxidative stress. We proposed the simulated sI/sR injury model of cardiomyocytes isolated from adult heart ventricles as a basic model for observing changes at the cellular level caused by sI/sR. The current study may constitute the foundation for further research on more advanced models.

\section{Materials and methods}

Cell culture. The cells of HCM, (commercially available, ScienCell Research Laboratories, Ink. LOT 16787, $>1 \times 10^{6}$ cells $/ \mathrm{ml}, 1 \mathrm{ml} /$ vial) isolated from adult heart ventricles were cultured in Dulbecco's Modified Eagle's Medium with the addition of Cardiac Myocytes Growth Supplement (ScienCell Research Laboratories, Ink.; LOT RNBD9247, LOT 16425, respectively), $5 \%$ fetal bovine serum, $100 \mathrm{u} / \mathrm{ml}$ penicillin, $100 \mu \mathrm{g} / \mathrm{ml}$ streptomycin (Sigma-Aldrich, Merck KGaA). The cell line was cultured at $37^{\circ} \mathrm{C}$ in a water-saturated, $5 \% \mathrm{CO}_{2}$ atmosphere. Cells passages were performed at $80 \%$ confluence by harvesting with $0.25 \%$ trypsin-EDTA (Sigma-Aldrich, Merck KGaA; LOT MS00JR).

Protocol for in vitro chemical ischemia and reperfusion. HCM underwent in vitro chemical ischemia. After $15 \mathrm{~min}$ of aerobic stabilization, cells were subjected to $15 \mathrm{~min}$ of chemical ischemia and then $20 \mathrm{~min}$ of aerobic reperfusion at room temperature (RT) with an atmosphere of $5 \% \mathrm{CO}_{2}$. Cells were subjected to aerobic stabilization in the HEPES buffer (5.5 mmol/1 4-(2-hydroxyethyl)-1-piperazineethanesulfonic acid, $63.7 \mathrm{mmol} / \mathrm{l} \mathrm{CaCl}_{2}, 5 \mathrm{mmol} / 1 \mathrm{KCl}, 2.1 \mathrm{mmol} / 1 \mathrm{MgCl}_{2}$, $5.5 \mathrm{mmol} / \mathrm{l}$ glucose, $10 \mathrm{mmol} / \mathrm{l}$ taurine) supplemented with $55 \mu \mathrm{mol} / \mathrm{CaCl}_{2}$ and $0.75 \mathrm{mg} / \mathrm{ml}$ bovine serum albumin (BSA, Sigma-Aldrich, Merck KGaA). After aerobic stabilization HEPES buffer was replaced (by centrifugation for $2 \mathrm{~min}$ at $1,500 \mathrm{x} \mathrm{g}$ at RT) with ischemia buffer (HEPES buffer containing $4.4 \mathrm{mmol} / 1$ 2-deoxyglucose and $4.0 \mathrm{mmol} / 1$ sodium cyanide (Sigma-Aldrich, Merck KGaA), which served as an inhibitor of electron transport chain). 15 min of chemical ischemia was established by measuring LDH activity (marker of cell damage) released from cells (data not showed). Next ischemia buffer was removed (by centrifugation for $2 \mathrm{~min}$ at $1,500 \mathrm{x} \mathrm{g}$ at RT) and the pellet was resuspended in fresh portion of HEPES buffer containing additional $55 \mu \mathrm{mol} / 1$ $\mathrm{CaCl}_{2}$ and $0.75 \mathrm{mg} / \mathrm{ml} \mathrm{BSA}$ at RT with an atmosphere of $5 \% \mathrm{CO}_{2}$ (reperfusion). Subsequently cells were centrifuged (for $5 \mathrm{~min}$ at $1,500 \mathrm{xg}$ at RT) and cells pellet was homogenized and stored at $-80^{\circ} \mathrm{C}$ until further analysis. The aerobic control group was maintained in aerobic conditions for $50 \mathrm{~min}$ (Fig. 1). 'N' number per one group (Aero/sI/sR) was established as cells collected from one culture flask, from the same passage to keep the samples homogeneous, treated under aerobic or chemical ischemia conditions, respectively. The procedure was developed in our laboratory (40).

Cell homogenization. Cells pellets were suspended in the homogenization buffer $(50 \mathrm{mmol} / 1$ Tris- $\mathrm{HCl}(\mathrm{pH} 7.4)$ containing $3.1 \mathrm{mmol} / 1$ sucrose, $1 \mathrm{mmol} / 1$ dithiothreitol, $10 \mu \mathrm{g} / \mathrm{ml}$ leupeptin, $10 \mu \mathrm{g} / \mathrm{ml}$ soybean trypsin inhibitor, $2 \mu \mathrm{g} / \mathrm{ml}$ aprotinin and $0.1 \%$ Triton X-100 (Sigma-Aldrich, Merck KGaA) on ice. Then, cells were degraded in three cycles of freezing in liquid nitrogen and thawing at $37^{\circ} \mathrm{C}$, and mechanically homogenized on ice (three times for $10 \mathrm{sec}$ ) using a hand-held homogenizer. Cell homogenates were centrifuged for $5 \mathrm{~min}(10000 \mathrm{x} \mathrm{g}$ at $4^{\circ} \mathrm{C}$ ) to collect supernatant (cell-conditioned medium) and then stored at $-80^{\circ} \mathrm{C}$ until further analysis.

Determination of protein concentration. Bradford Protein Assay (Bio-Rad Laboratories, Inc.; LOT \#SLBF1982V) was used to determine protein concentration in cells homogenates. BSA (heat shock fraction, $\geq 98 \%$, Sigma-Aldrich Merck KGaA) served as a protein standard.

Assessment of LDH activity. Lactate dehydrogenase activity assay kit (Sigma-Aldrich,Merck KGaA; LOT \#4J20K07260) was used to determine LDH activity in cell-conditioned medium from HCM collected after chemical ischemia, following the manufacturer's instructions. LDH catalyzed the interconversion of pyruvate and lactate with the reduction of nicotinamide adenine dinucleotide to reduced nicotinamide adenine dinucleotide. This reaction was detected by colorimetric assay (at $450 \mathrm{~nm}$ ). LDH served as a marker of cell injury because of its cytoplasmic localization and immediate release into extracellular space during cell membrane damage/increased permeability.

MYL4, MYL3 and MMP-2 mRNA expression. Total RNA was isolated from HCM pellet using TRIZOL reagent (Thermo Fisher Scientific.; LOT 18132201) in accordance with the manufacturer's instructions. $2 \mu \mathrm{g}$ of pure RNA was reverse transcribed to cDNA using iScript cDNA Synthesis Kit (Bio-Rad Laboratories, Inc.; LOT 64393525). The expression of following genes: $M Y L 4, M Y L 3$ and $M M P-2$ in relation to glucose-6-phosphate dehydrogenase $(G 6 P D)$ was analyzed by RQ-PCR using CFX96 Touch (Bio-Rad Laboratories, Inc.). iTaq Universal Sybr Green Supermix (Bio-Rad Laboratories, Inc.; LOT 64326845), forward and reverse primers (final concentration $0.1 \mu \mathrm{m} / 1)$, Ultra Pure DEPC-Treated water (Thermo Fisher Scientific) and cDNA (100 ng) were used in a 


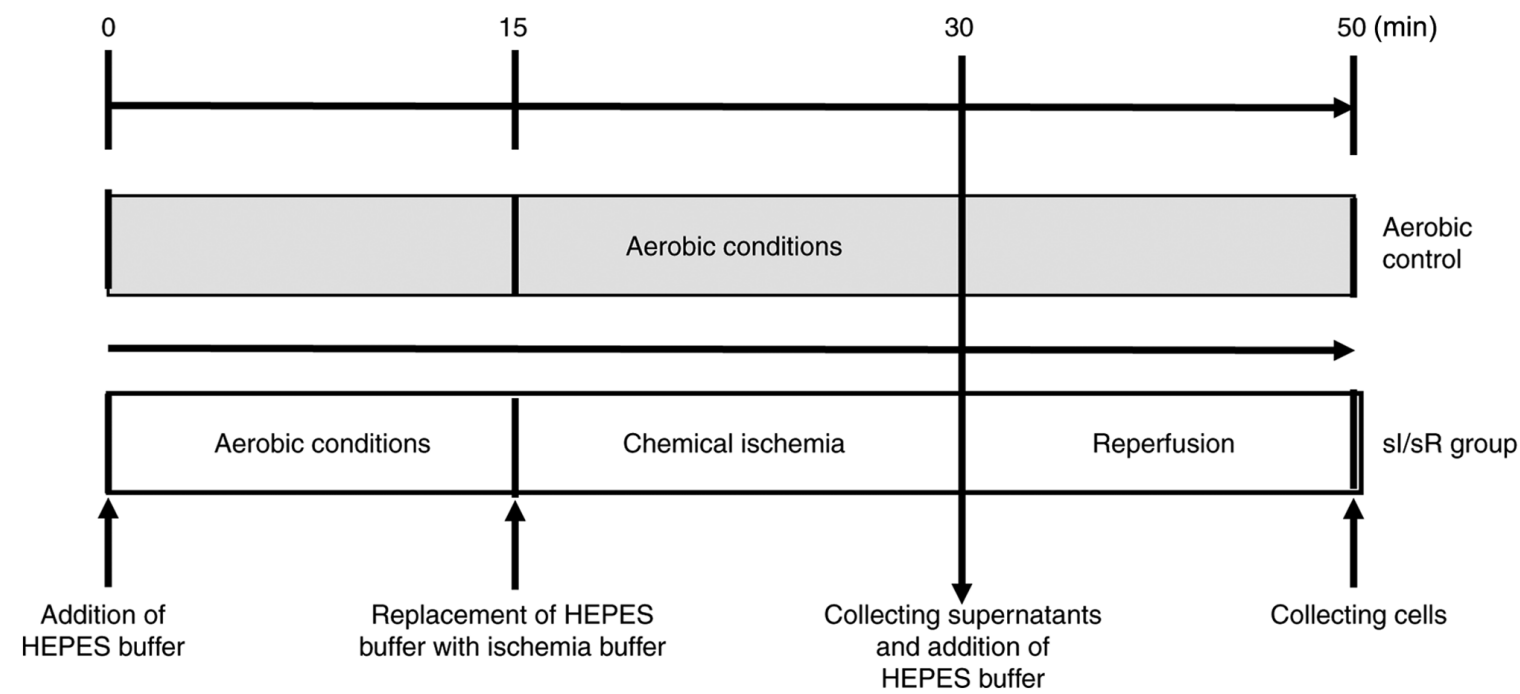

Figure 1.Experimental protocol for the sI/sR group and aerobic control.sI/sR, simulated ischemia and simulated reperfusion; HEPES, 4-(2-hydroxyethyl)-1-piperazineethanesulfonic acid.

final volume of $30 \mu \mathrm{l}$. The 5'-3' sequences of primers were as follows: MYL4 F: AAGATCACCTACGGCCAGTG, MYL4 R: CCCTCCACGAAGTCCTCATA, MYL3 F: TACTTACAG CCCCCAATGGC, MYL3 R: TCTTGCCCAGCCATCAAC TT, MMP-2 F: ATCCAGACTTCCTCAGGCGG, MMP-2 R: CCTGGCAATCCCTTTGTATGTT. The amount of mRNAs in relation to $G 6 P D$ was calculated as $2^{-\Delta \mathrm{Ct}}$. The relative expression of respective genes were compared in cells exposed to aerobic conditions and cells subjected to $\mathrm{sI} / \mathrm{sR}$.

Analysis of MMP-2 concentration in cell homogenates. MMP-2 concentration in HCM homogenates was measured using quantitative Quantikine ELISA Assay for Total MMP-2 (R\&D Systems, Inc.; LOT P256537) in accordance with the manufacturer's instruction. Total MMP-2 Quantikine ELISA assay recognized recombinant MMP-2, active and pro-MMP-2, as well as tissue inhibitors of matrix metalloproteinase complexed MMP-2. MMP-2 was immobilized with monoclonal antibody specific to this protein and detected using anti-Total-MMP-2 polyclonal antibody conjugated to Streptavidin-Horse Radish Peroxidase (HRP). Then 3,3',5, '-Tetramethylbenzidine (TMB) substrate solution was added to trigger the reaction. A minimum detectable dose was $0.033 \mathrm{ng} / \mathrm{ml}$. MMP-2 concentration in cell homogenates was expressed as ng per $\mu \mathrm{g}$ of total protein.

Determination of MMP-2 activity. MMP-2 activity was examined by gelatin zymography with the modified protocol of Heussen and Dowdle $(40,41)$. Protein concentrations in $\mathrm{HCM}$ and cell-conditioned medium collected after simulated ischemia were measured using Bradford Protein Assay. HCM homogenate and cell-conditioned medium from each sample were adjusted to contain the same protein concentration with distilled water, and mixed with 4x Laemmli Sample Buffer (Bio-Rad Laboratories, Inc.) in a ratio of 4:1 (v:v). Samples containing $20 \mu \mathrm{g}$ of protein were applied to $8 \%$ polyacrylamide gel copolymerized with gelatin $(2 \mathrm{mg} / \mathrm{ml})$ and $0.1 \%$ sodium dodecyl sulfate (SDS, denaturing, but not reducing conditions). After electrophoresis, gels were rinsed (three times for $20 \mathrm{~min}$ ) in $2.5 \%$ Triton X-100 to remove SDS. Then, gels were placed in the incubation buffer $(50 \mathrm{~mol} / \mathrm{l}$ Tris- $\mathrm{HCl} \mathrm{pH} 7.5,5 \mathrm{mmol} / \mathrm{l}$ $\mathrm{CaCl}_{2}, 200 \mathrm{mmol} / \mathrm{l} \mathrm{NaCl}, 0.05 \% \mathrm{NaN}_{3}$ ) for $18 \mathrm{~h}$ at $37^{\circ} \mathrm{C}$. After digestion of gelatin, gels were staining for $2 \mathrm{~h}(0.5 \%$ Coomassie Brilliant Blue R-250, 30\% methanol, 10\% acetic acid) and destaining (30\% methanol, 10\% acetic acid) until bands were clearly visible (Sigma-Aldrich, Merck KGaA). MMP-2 activity was visualized as dark bands on a bright background. Zymograms were scanned using GS-800 Calibrated Densitometer (model PowerLook 2100 XL-USB) and analyzed using Quantity One v. 4.6.9 software (Bio-Rad Laboratories, Inc.). The relative activity of MMP-2 was established and expressed in $\mathrm{AU}$ as an activity per $\mu \mathrm{g}$ of total protein.

Analysis of ALCl and VLCl concentration in cell homogenates. Atrial isoform of myosin light chain 1 (ALC1) concentration in HCM homogenates was determined using Human Myosin Light Chain 4 ELISA Kit (Bioassay Technology Laboratory; LOT 1812006). The concentration of ventricular isoform of myosin light chain 1 (VLC1) in HCM homogenates was determined using Human Myosin Light Chain 3 ELISA kit (Bioassay Technology Laboratory; LOT 201908009). Briefly, capture antibodies bound to ALC1/VLC1 from cell homogenates which were detected by biotinylated antibodies. Then, HRP was conjugated to the biotinylated ALC1/VLC1 antibody. TMB substrate solution was added to enable complex visualization. A minimum detectable concentration of ALC1 and VLC1 ELISA tests was $0.024 \mathrm{ng} / \mathrm{ml}$ and $12.93 \mathrm{ng} / \mathrm{l}$, respectively. ALC1/VLC1 in cell homogenates were expressed as ng per $\mu \mathrm{g}$ of total protein.

Analysis of ALC1 and VLC1 by immunofluorescence microscopy. Indirect immunofluorescence method was used to determine the expression of ALC1 and VLC1 in cardiomyocytes after sI/sR. Cells were cultured at 24-well Cell Culture Plate (Greiner Bio-One, Cellstar) to reach $90 \%$ confluence, as previously described. Cells underwent in vitro chemical ischemia on culture plate according to the procedure described above (simultaneously aerobic control was 
maintained in aerobic conditions). Next $4 \%$ paraformaldehyde (Sigma-Aldrich, Merck KGaA) was added to each well in order to fix the cells. After 15 min of incubation at RT, cells were washed with phosphate-buffered saline (PBS). Then blocking buffer (10\% goat serum, $1 \%$ BSA, 0.3 m glycine, $0.1 \%$ Triton $\mathrm{X}-100$ in PBS) was added to each well. Plate was incubated for $1 \mathrm{~h}$ at RT and then washed with PBS. Plate was incubated overnight at $4^{\circ} \mathrm{C}$ with Rabbit Anti-MYL4 Antibody (Bioassay Technology Laboratory; LOT BT-AP05702) and Mouse Anti-MYL3 Antibody (Invitrogen; LOT UH2823151). After overnight incubation plate was rinsed with PBS. Then Donkey anti-Rabbit IgG conjugated to fluorochrome DyLight 488 (Abcam,; LOT GR177576-7) and Goat anti-Mouse IgG conjugated to fluorochrome DyLight 550 (Abcam; LOT GR155905-3) were added to the wells for $45 \mathrm{~min}$ in the dark to visualize the expression of ALC1 (green fluorescence) and VLC1 (red fluorescence), respectively. After wash, DAPI (4', 6-diamidino-2-phenylindole, Sigma-Aldrich, Merck KGaA ; LOT \#034M4030V) was added to wells to stain cells' nuclei (blue fluorescence). After $15 \mathrm{~min}$ of incubation at RT in the dark and washed with PBS the emitted signal was read using Multifunction Reader Spark TK Biotech 2017 (Tecan Austria $\mathrm{GmbH}$ ), Zoe Fluorescent Cell Imager (magnification x200, Bio-Rad Laboratories, Inc.) and Thunder Leica Imager (magnification x400, Leica Microsystems). The excitation and emission wavelength for DyLight 488 was 493 and $518 \mathrm{~nm}$, respectively. The excitation and emission wavelength for DyLight 550 was 562 and $576 \mathrm{~nm}$, respectively. The excitation and emission wavelength for DAPI was 358 and $461 \mathrm{~nm}$, respectively. The cell expression of ALC1 and VLC1 in cardiomyocytes were expressed in arbitrary units (AU) as expression normalized to the total number of cells in each well determined by staining with DAPI.

Statistical analysis. The statistical analysis of the results was performed in GraphPad Prism v. 5. Shapiro-Wilk normality test or Kolmogorov-Smirnov test was used to estimate the normality of variances changes. Then results were analyzed by appropriate tests: unpaired t-test or Mann-Whitney U test. Correlations were assessed using Pearson's or Spearman's tests, as appropriate. The results were expressed as mean \pm standard error of the mean. $\mathrm{P}<0.05$ was regarded as a statistically significant difference. In selected tests we used up to 20 flasks per group (Aero or sI/sR, respectively)-it was based on the Power Analysis test (alpha $=0.05$, power $=0.80$ ), which was performed with the preliminary studies for each test. The difference in ' $N$ ' numbers between experiments also follows from the fact that some part of cells died, then the ' $N$ ' number had to be reduced. Part of results had to be removed from the analysis as well, as they were 'significant outliers' according to Grubbs test. Despite the different ' $N$ ' number, we obtained statistically significant differences in the presented experiments.

\section{Results}

LDH activity in cell-conditioned medium as a marker of cell injury. LDH activity in cell-conditioned medium of sI/sR group (as a marker of ischemic cells damage) was significantly increased in comparison to the aerobic (Aero) group $(\mathrm{P}=0.02$, $n=20$ ) (Fig. 2). It confirmed the induction of sI/sR.

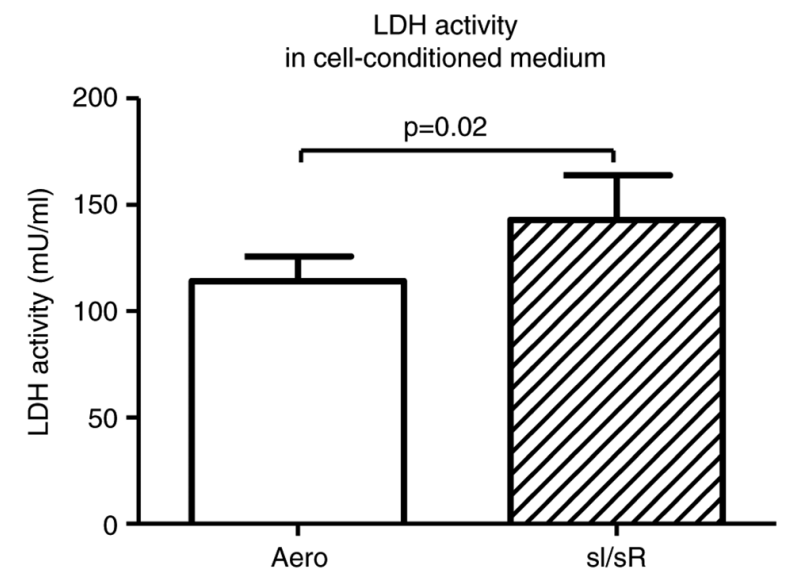

Figure 2. LDH activity in the cell-conditioned medium of cells subjected to $\mathrm{sI} / \mathrm{sR}$ and aerobic conditions. Data are presented as the mean \pm SEM $(n=20)$. LDH, lactate dehydrogenase. sI/sR, simulated ischemia and simulated reperfusion; aero, aerobic control.

MMP-2 mRNA expression, synthesis and activity in myocytes subjected to sI/sR. The expression of MMP-2 gene $(\mathrm{P}<0.001, \mathrm{n}=7)$, as well as MMP-2 concentration $(\mathrm{P}=0.03, \mathrm{n}=8)$ and activity $(\mathrm{P}=0.03, \mathrm{n}=6)$ in $\mathrm{HCM}$ were decreased in $\mathrm{sI} / \mathrm{sR}$ group in comparison to Aero group (Fig. 3A-C). However, MMP-2 activity measured in cell-conditioned medium collected after chemical ischemia and before reperfusion was significantly higher in sI/sR group $(\mathrm{P}=0.006, \mathrm{n}=10)($ Fig. 3D and E).

MYL4, MYL3 mRNA expression and ALC1, VLC1 concentrations in cell homogenates. MYL4 gene (coding ALC1) expression level was significantly higher in sI/sR group in comparison to Aero group $(\mathrm{P}=0.03$, $\mathrm{n}=14)$ (Fig. $4 \mathrm{~A})$. In contrary, the expression of MYL3 gene (coding VLC1) was decreased in sI/sR group $(\mathrm{P}=0.008, \mathrm{n}=14)(\mathrm{Fig}$. 4B). This was confirmed by negative correlation of MYL4 and MYL3 genes expressions $(\mathrm{P}=0.01, \mathrm{r}=0.34)$ (Fig. 4C). Increased expression of MYL4 mRNA negatively correlated with expression of $M M P-2(\mathrm{P}=0.04, \mathrm{r}=0.36)$, while expression of MYL3 mRNA correlated positively with $M M P-2$ expression $(\mathrm{P}<0.001, \mathrm{r}=0.67)$ (Fig. 4D).

The concentration of ALC1 in HCM was significantly higher in $\mathrm{sI} / \mathrm{sR}$ group in comparison to Aero group $(\mathrm{P}<0.001, \mathrm{n}=21)$. The difference in VLC1 content in HCM was not significant between Aero and $\mathrm{sI} / \mathrm{sR}$ groups $(\mathrm{P}=0.18, \mathrm{n}=14)$ (Fig. 5A and B). The negative correlation between ALC1 and MMP-2 concentration in cells was found $(\mathrm{P}=0.003, \mathrm{r}=0.44)$ (Fig. 5C).

Cell expression of ALC1 and VLC1 in myocytes. Indirect immunofluorescence testing showed that the number of HCM after sI/sR was much lower in comparison to Aero group $(\mathrm{P}=0.003, \mathrm{n}=12$ ) (Fig. 6A). 4', 6-diamidyno-2-phenyloindole (DAPI) stained all nuclei in fixed cells-result of DAPI emission served as a marker of cells number. sI/sR group of myocytes showed higher cell expression of ALC1 $(\mathrm{P}=0.01, \mathrm{n}=12)$ (Fig. 6B and $\mathrm{E})$ and lower cell expression of VLC1 $(\mathrm{P}=0.04, \mathrm{n}=12)$ (Fig. 6C and F) than the Aero group. This was confirmed by their negative correlation $(\mathrm{P}=0.02, \mathrm{r}=0.46)$ (Fig. 6D). 
A

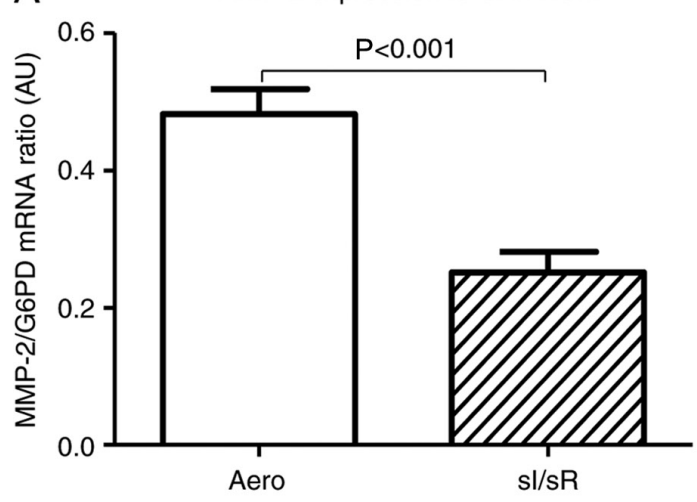

C



B

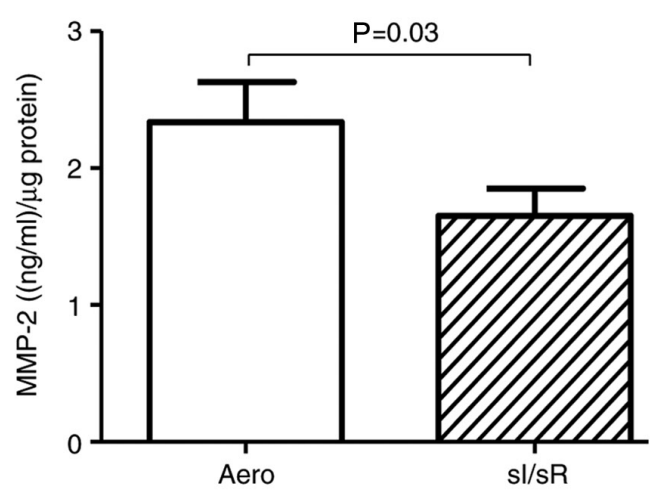

D MMP-2 activity

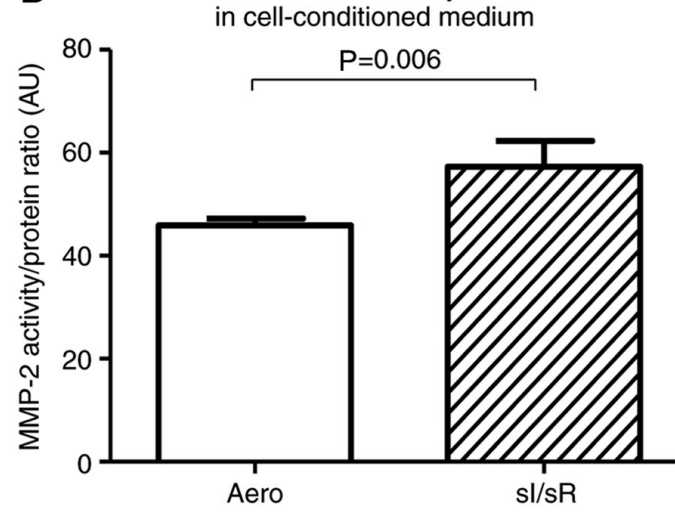

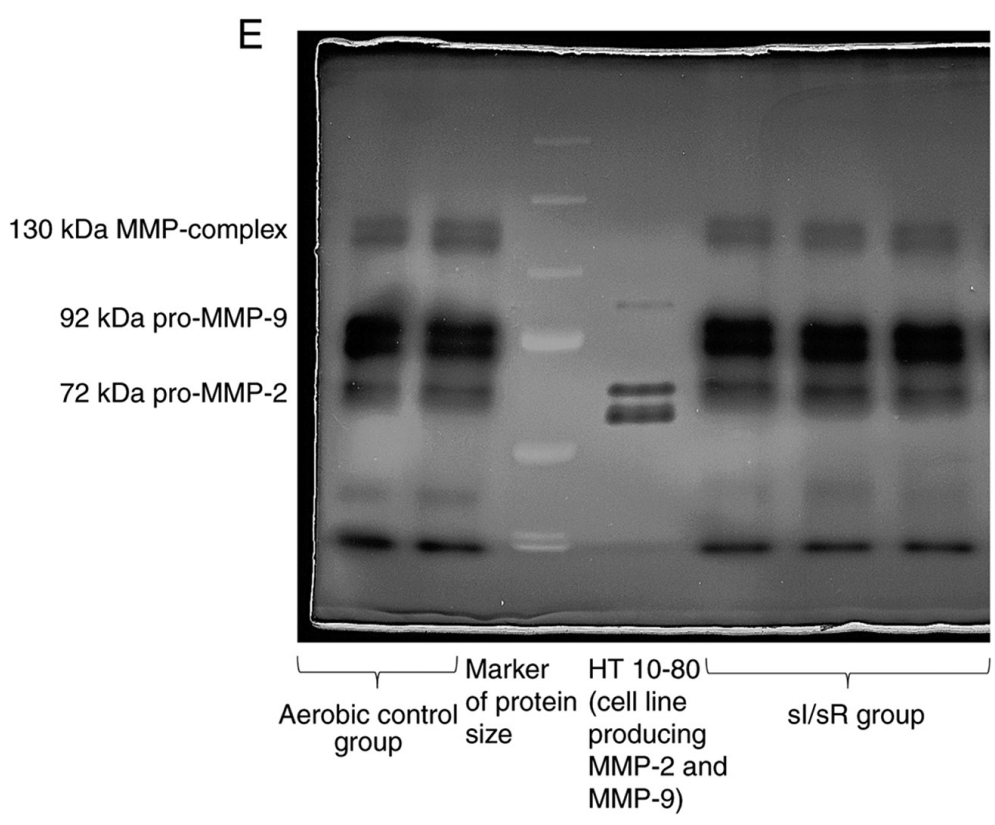

Figure 3. MMP-2 measurement. (A) $M M P-2$ mRNA expression normalized to the $G 6 P D$ gene (n=7). (B) MMP-2 concentration in cell homogenates normalized to the content of protein in each sample $(n=8)$. (C) MMP-2 activity in HCM $(n=6)$. (D) MMP-2 activity in the cell-conditioned medium of HCM (n=10). (E) Representative zymogram of MMP-2 activity in cell-cultured medium. Data are presented as the mean \pm SEM. G6PD, glucose-6-phosphate dehydrogenase; HCM, human cardiomyocytes; sI/sR, simulated ischemia and simulated reperfusion; aero, aerobic control; AU, arbitrary units.

\section{Discussion}

Human myocardium contains a wide range of proteins isoforms responsible for the heart contractile function $(38,42-45)$. During the development of cardiac pathologies, changes in the contractile apparatus of cardiomyocytes striving to maintain myocardial contractile activity occur $(38,46)$. Transformation of atrial and ventricular types of myosin is one of the detectable alterations (47). Expression of MHC does not change substantially in adult hypertrophic ventricle, while ALC1 partially replaces the endogenous VLC1 isoform $(9,22,35)$. As a result of the increased effort, cardiomyocytes undergo both hypertrophy and changes in the cell phenotype. Adult myocardial cells strive for restoring the original protein synthesis 
A

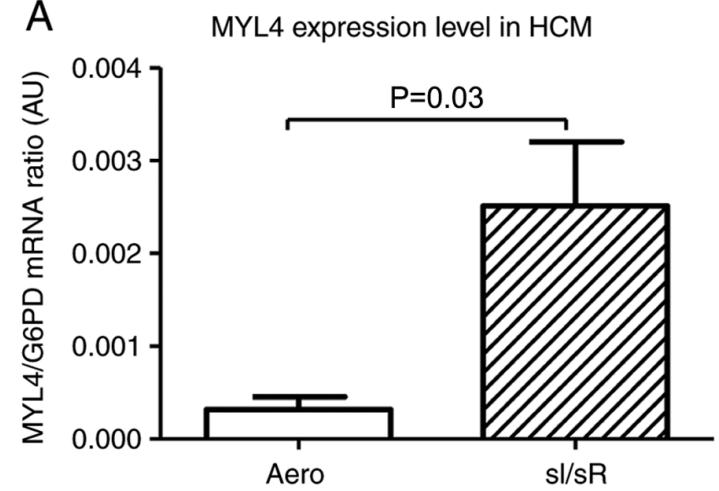

C

Correlation between MYL4 and MYL3 gene expression

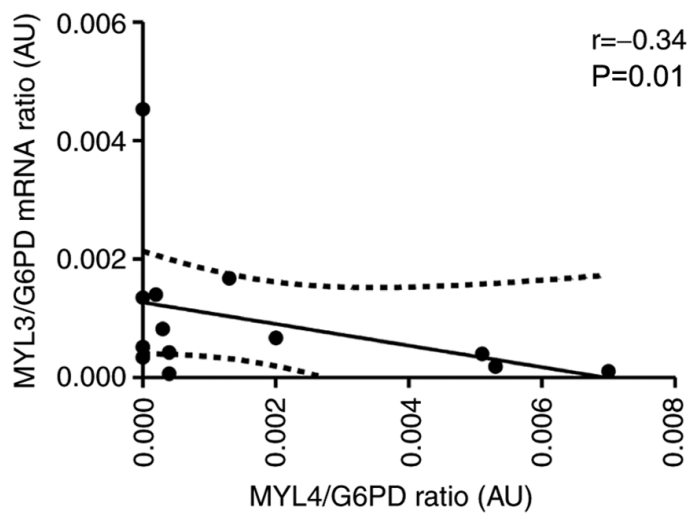

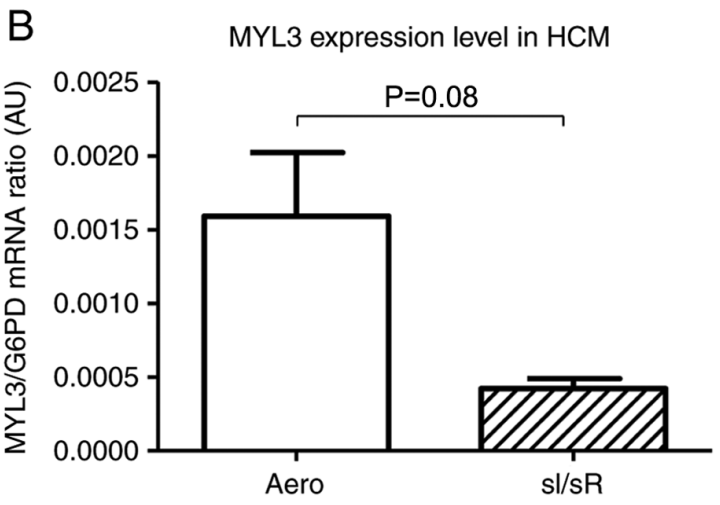

D Correlation between MYL4, MYL3 and MMP-2 genes expression

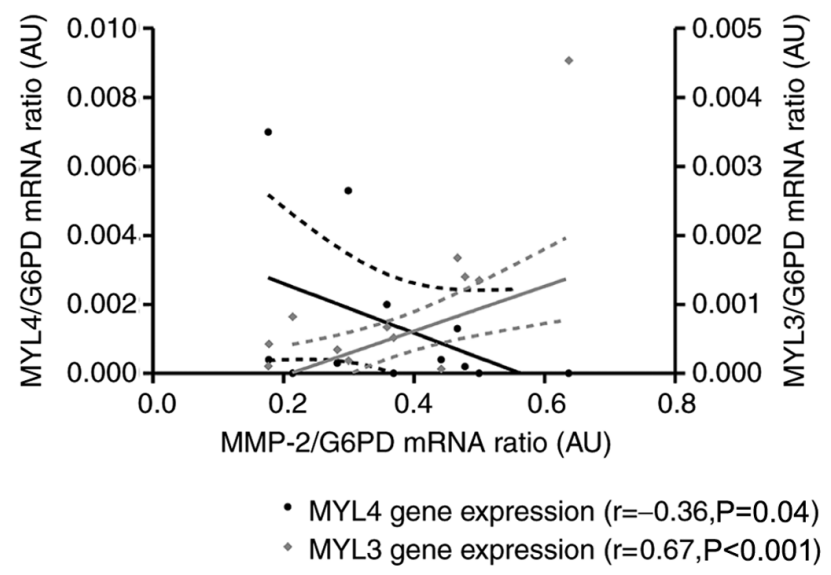

Figure 4. MYL4 and MYL3 mRNA expression. (A) MYL4 and (B) MYL3 mRNA expression was normalized to the G6PD gene (n=14). Subsequently, the correlation between (C) MYL4 and MYL3 (n=13), and (D) MYL4, MYL3 and MMP-2 gene expression was assessed (n=12). Solid lines represent the residual plot. Dotted lines represent the 95\% confidence interval. Data are presented as the mean \pm SEM. MYL4, atrial light chain 1 gene; MYL3, myosin light chain 3; G6PD, glucose-6-phosphate dehydrogenase; HCM, human cardiomyocytes; sI/sR, simulated ischemia and simulated reperfusion; aero, aerobic control; $\mathrm{AU}$, arbitrary units.

pattern previously observed in ontogenesis, to regain their original ability to perform proper function. The 'fetal gene program' is induced which results in reduction of the expression of adult isoforms of several heart proteins and increase in the expression of particular genes such as MYL4, which is known as a key gene responsible for atrial contractile, structural and electrical integrity $(9,13,47)$. Fujimoto et al (1993) showed that ALC1 was strongly expressed in the overloaded adult ventricle as well as in the fetal ventricle (48). They indicated that proteins expressed in the fetal stage reappeared in an overloaded ventricle (48).

The main aim of this research was to explore, whether the expression of ALC1 is increased in the simulated ischemia/reperfusion injury of ventricular cardiomyocytes. We showed that sI/sR induced changes in MYL4 and MYL3 at the level of genes expression and protein synthesis. The expression of MYL4 gene (encoding atrial form of MLC1) was significantly increased in cardiomyocytes subjected to sI/sR, while the expression of MYL3 gene (encoding ventricular form of MLC1) was significantly reduced in comparison to cells maintained in aerobic conditions. In addition, a negative correlation between MYL4 and MYL3 was observed, which may confirm that the simultaneous change in the isoform expression occurred as an adaptation of myocyte contractile apparatus to sI/sR conditions and an activation of 'fetal gene program' (20).

Diffee et al (2003) presented the results of real-time quantitative reverse transcriptase polymerase chain reaction (RQ-PCR) for expression of MYL4 and MYL3 genes of the hearts of subjects undergoing exercise training, with respect to the control tissue from heart ventricles of healthy subjects (47). They observed an increase in mRNA expression and ALC1 production in those, who were forced through physical exercises. In the consequences, this was associated with enhanced cardiac contractile function through increased calcium sensitivity of tension and increased power output (47). However, in contrary to our results, the expression of MYL3 did not decrease. It suggested that overexpression of MYL4 in myocardium resulted in the inclusion of the recently synthesized ALC1 isoform in myofilament despite no change in VLC1 expression after exercise training (47). Ritter et al (1999) demonstrated that replacement of VLC1 with ALC1 in transgenic mice occurred at the level of protein synthesis, despite the changes being visible in gene expression in rats subjected to the endurance training (18). This means that the mechanism is not well understood and still requires further research.

In our research, changes of MYL4 and MYL3 mRNA expressions were accompanied with their synthesis in ventricle 
A

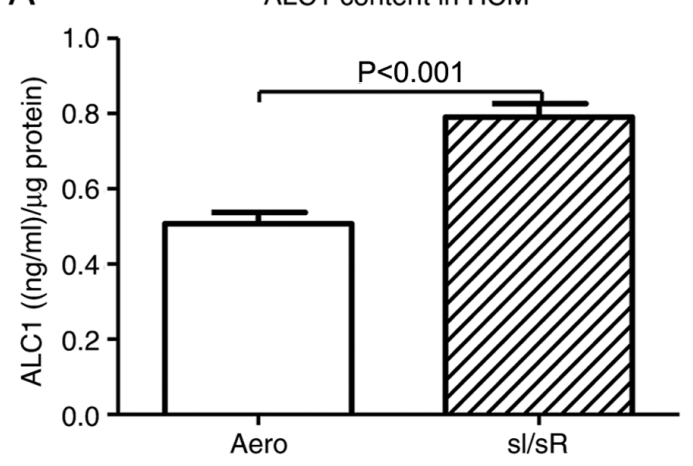

B

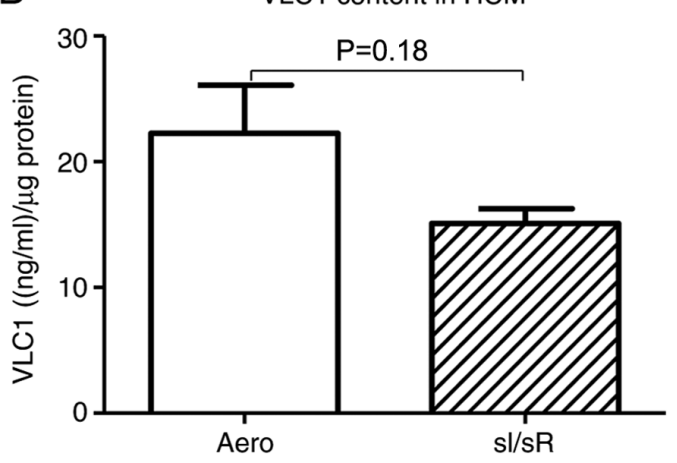



- ALC1 content $(r=-0.44, P=0.003)$

- VLC1 content $(r=0.29, P=0.13)$

Figure 5. Synthesis of ALC1/VLC1 in myocytes. The concentration of (A) ALC1 and (B) VLC1 in HCM was measured using ELISA and normalized to the protein content of each sample ( $\mathrm{n}=14-21$ ). (C) The correlation between ALC1 and VLC1 content and MMP-2 concentration in cells was assessed ( $\mathrm{n}=14-6)$. Data are presented as the mean \pm SEM. ALC1, atrial light chain 1; VLC1, ventricular light chain 1; HCM, human cardiomyocytes; sI/sR, simulated ischemia and simulated reperfusion; aero, aerobic control.

myocytes. ALC1 concentration and tissue expression were significantly increased in cardiomyocytes subjected to oxidative stress. An immunofluorescence study confirmed negative correlation of ALC1 and VLC1 expression in cardiomyocytes. There are previous reports confirming compensatory mechanism observed in our study. Nakao et al (1992) showed that expression of ALC1 was increased in the heart ventricles with progressive heart failure and ventricular aneurysmectomy in patients with old myocardial infarction in their medical history. It was considered as a regional adaptation to the increased workload (19). Machackova et al (2006) observed an increased expression of ALC1 in the ventricles of patients with familial hypertrophic cardiomyopathy-ALC1 partially replaced VLC1, leading to increased cross-bridge cycling kinetics (16). Similarly, Morano et al (1996) observed, that increased expression of ALC1 modulated cross-bridge cycling kinetics by accelerating shortening velocity and isometric tension production (8). Diffee et al (2003) demonstrated that the level of changes in systolic properties significantly correlated with the increase of ALC1 expression (47). The replacement of VLC1 with ALC1 is a reversible phenomenon $(8,12,14)$. This may indicate that changes in the expression of MLC1 isoforms are the basic molecular mechanism for adjustments in the systolic function during the pathological state $(24,47,49)$.
Myocardial injury during $I / R$ is a complex and multifactorial process in which reactive oxygen species activate MMP-2 (28-31,50), which in turn degrades the contractile proteins such as MLC1 $(25,27,30,50-52)$. We previously showed that this process led to contractility disorders $(53,54)$. In the current study, MMP-2 gene expression as well as its concentration in HCM homogenates and MMP-2 activity in HCM and cell-conditioned medium were examined. We showed that mRNA expression, synthesis and activity of MMP-2 in HCM were decreased in the sI/sR group, however, MMP-2 activity measured in cell-conditioned medium collected after ischemia was higher in sI/sR group. This confirmed that MMP-2 was released into the extracellular space due to cells damage.

Biały et al (2018) described similar relationship of MMP-2 and I/R (40). Reduced MMP-2 activity measured in HCM homogenates was observed, suggesting the release of MMP-2 into extracellular space (40). They also showed significantly reduced metabolic activity of myocytes, implying their inability to produce energy and, consequently, metabolic failure and death (40). Cheung et al (2000) also proved that in first minutes after reperfusion had started there was observed an acute enhancement in MMP-2 release into the coronary effluents from the hearts as shown by increase MMP-2 activity in coronary effluents (55), which was 
A

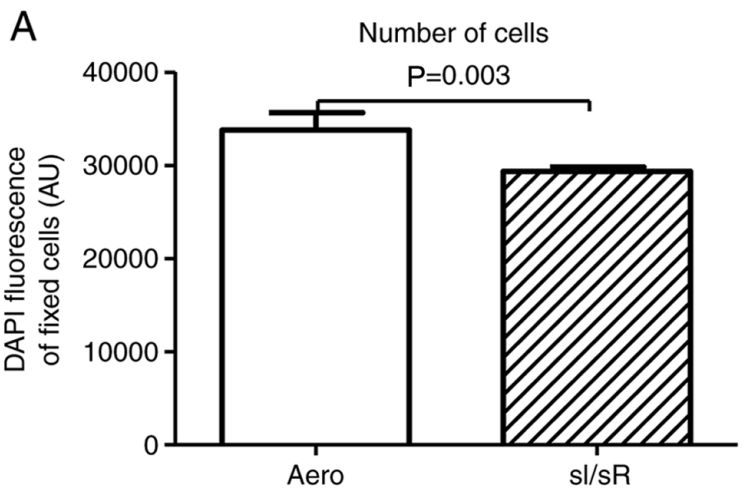

C

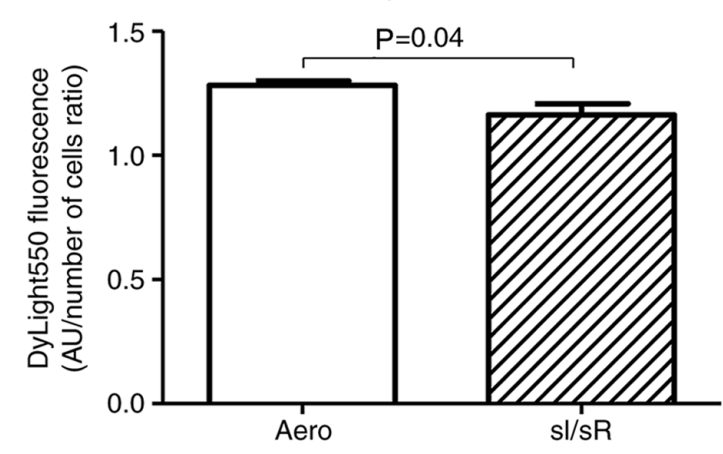

$\mathrm{E}$

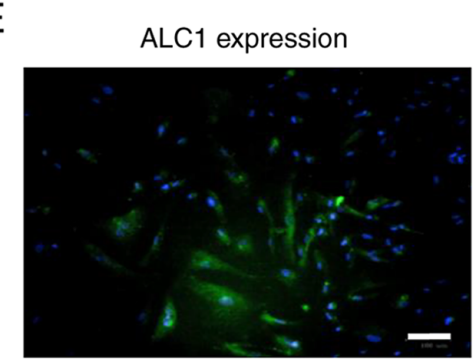

Aero group

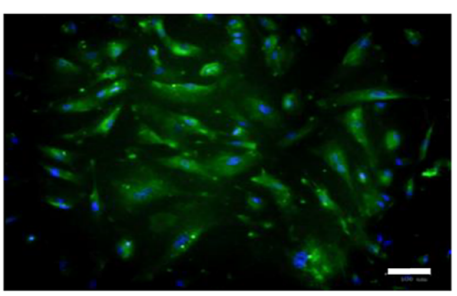

sl/sR group
B Cell expression of ALC1

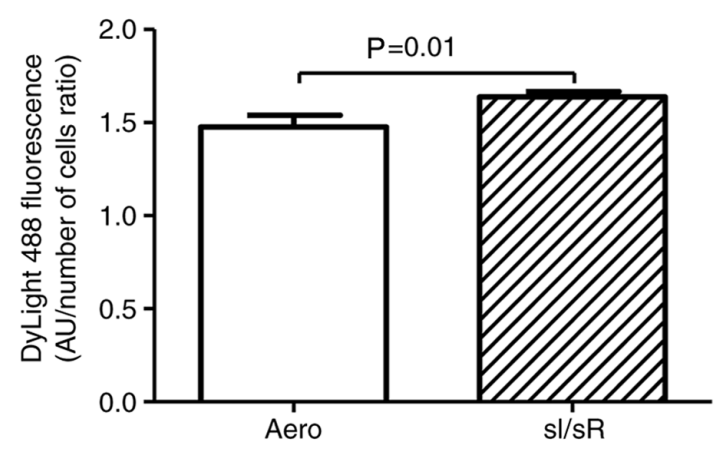

D Correlation between ALC1 and VLC1 cell expression

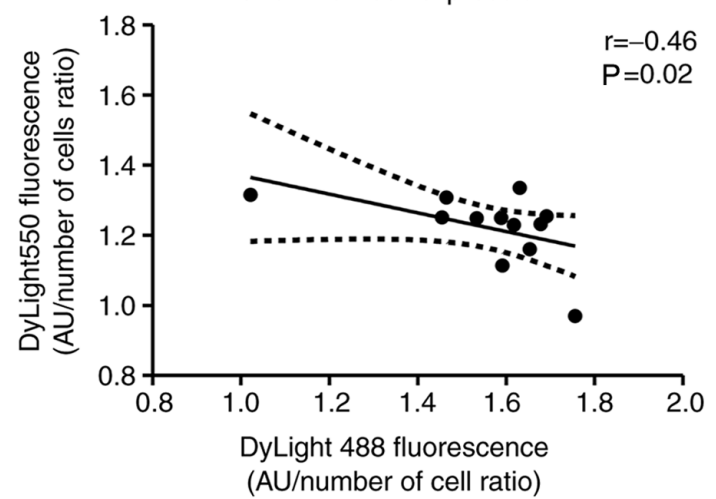

$\mathrm{F}$



Aero group

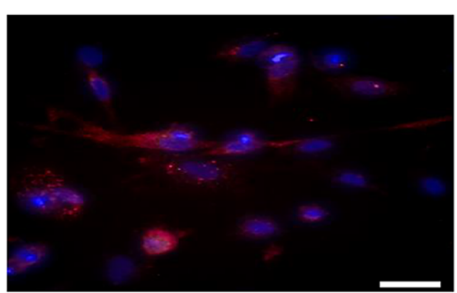

sl/sR group

Figure 6. Fluorescence microscopy. (A) The number of cells fixed with paraformaldehyde was assessed by measuring the fluorescence of cell nuclei stained with DAPI (blue fluorescence) $(\mathrm{n}=12)$. (B) the HCM expression of ALC1 was assessed by measuring the green fluorescence of fixed cells stained with anti-ALC1 antibodies and DyLight 488 normalized to the total number of cells (blue fluorescence) (n=12). (C) The HCM expression of VLC1 was assessed by measuring the red fluorescence of fixed cells stained with anti-VLC1 antibodies and DyLight 550 normalized to the total number of cells (blue fluorescence) $(n=12)$. (D) The correlation between ALC1 and VLC1 cell expression was established $(n=12)$. (E) Immunofluorescence staining of fixed cells for ALC1 (green fluorescence) and DAPI for nuclei (blue fluorescence) was performed (magnification, x200; scale bar, $100 \mu \mathrm{m}$ ). (F) immunofluorescence staining of fixed cells for VLC1 (red fluorescence) and DAPI for nuclei (blue fluorescence) (magnification, x400; scale bar, $100 \mu \mathrm{m}$ ). Solid lines represent the residual plot. Dotted lines represent the $95 \%$ confidence interval. Data are presented as the mean \pm SEM. HCM, human cardiomyocytes; ALC1, atrial light chain 1; VLC1, ventricular light chain 1; sI/sR, simulated ischemia and simulated reperfusion; aero, aerobic control; AU, arbitrary units.

consistent with our results. Ben-Yosef et al (2002) showed that MMP-2 activity changed from reduced after $6 \mathrm{~h}$ of hypoxia to increased after $24 \mathrm{~h}$ during remodelling of the extracellular matrix after I/R (56). Our study showed that both $15 \mathrm{~min}$ of chemical ischemia and $20 \mathrm{~min}$ of reperfusion led to the increased MMP-2 activity in cell-conditioned medium and decreased MMP-2 level in cells homogenates, confirming myocytes damage.

Bil-Lula et al (2018) also showed that increased synthesis of MMP-2 during I/R was associated with a decrease in 
VLC1 concentration by about $50 \%$ in cardiomyocytes of ventricles (23). Importantly, the $M M P-2$ gene expression in current study positively correlated with the expression of MYL3 gene and negatively with the expression of MYL4 gene. Moreover, a negative correlation between ALC1 concentration and MMP-2 content in cell homogenates may suggest that there is a relationship between ALC1 and MMP-2 activity, but this needs further investigation, as is only a speculation now.

In conclusion, the above data showed that the expression changes of $\mathrm{ALCl}$ and $\mathrm{VLCl}$ in an adult ventricle myocytes during simulated ischemia/reperfusion injury may be induced by the 'fetal genes expression program' as an attempt to adapt to sI/sR conditions. Described mechanism may lead to an improvement in heart function, but this needs further investigation. Moreover, data revealed that there is a relationship between ALC1 and MMP-2 activity, but this also needs further investigation. This preliminary study may provide the foundation for further studies on cardiac function, particularly cardiomyocyte contractility and actin - myosin interactions, on more advanced I/R models.

\section{Acknowledgements}

Not applicable.

\section{Funding}

This research was funded by the National Science Centre, Poland (grant no. UMO-2016/23/B/NZ3/03151).

\section{Availability of data and materials}

The datasets used and/or analyzed during the current study are available from the corresponding author on reasonable request.

\section{Authors' contributions}

$\mathrm{MB}$ and IBL conceived the current study. $\mathrm{MB}, \mathrm{AO}$ and $\mathrm{KH}$ performed the experiments and stored data on external drives. $\mathrm{MB}, \mathrm{AKZ}, \mathrm{AO}, \mathrm{KH}$ and IBL contributed to data analysis, investigation and methodology. $\mathrm{MB}$ and $\mathrm{AO}$ confirm the authenticity of all the raw data. AKZ and IBL coordinated funding to the project. MB and IBL contributed to project administration, supervision and construction of the final manuscript. MB contributed resources and conceived the original draft of the manuscript. IBL critically revised the manuscript. All authors read and approved the final manuscript.

\section{Ethics approval and consent to participate}

Not applicable.

\section{Patient consent for publication}

Not applicable.

\section{Competing interests}

The authors declare that they have no competing interests.

\section{References}

1. Abdelaziz AI, Segaric J, Bartsch H, Petzhold D, Schlegel WP, Kott M, Seefeldt I, Klose J, Bader M, Haase H and Morano I: Functional characterization of the human atrial essential myosin light chain (hALC-1) in a transgenic rat model. J Mol Med (Berl) 82: 265-274, 2004.

2. Gudbjartsson DF, Holm H, Sulem P, Masson G, Oddsson A, Magnusson OT, Saemundsdottir J, Helgadottir HT, Helgason H, Johannsdottir $\mathrm{H}$, et al: A frameshift deletion in the sarcomere gene MYL4 causes early-onset familial atrial fibrillation. Eur Heart J 38: 27-34, 2017.

3. Petzhold D, Lossie J, Keller S, Werner S, Haase H and Morano I: Human essential myosin light chain isoforms revealed distinct myosin binding, sarcomeric sorting, and inotropic activity. Cardiovasc Res 90: 513-520, 2011.

4. Cadete VJJ, Arcand SA, Lin HB and Sawicki G: Synergistic protection of MLC 1 against cardiac ischemia/reperfusioninduced degradation: A novel therapeutic concept for the future. Future Med Chem 5: 389-398, 2013.

5. Zhang C, Wang G, Ji Z, Liu Z, Hou L, Liu G and Wang J: Molecular cloning, characterisation and mRNA expression analysis of the sheep myosin light chain 1 gene. Gene 569: 51-59, 2015.

6. Reiser PJ: Current understanding of conventional and novel co-expression patterns of mammalian sarcomeric myosin heavy chains and light chains. Arch Biochem Biophys 662: 129-133, 2019.

7. Kurabayashi M, Komuro I, Tsuchimochi H, Takaku F and Yazaki Y: Molecular cloning and characterization of human atrial and ventricular myosin alkali light chain cDNA clones. J Biol Chem 263: 13930-13936, 1988.

8. Morano M, Zacharzowski U, Maier M, Lange PE, Alexi-Meskishvili V, Haase $\mathrm{H}$ and Morano I: Regulation of human heart contractility by essential myosin light chain isoforms. J Clin Invest 98: 467-473, 1996.

9. Schaub MC, Hefti MA, Zuellig RA and Morano I: Modulation of contractility in human cardiac hypertrophy by myosin essential light chain isoforms. Cardiovasc Res 37: 381-404, 1998.

10. Szczesna D: Regulatory light chains of striated muscle myosin. Structure, function and malfunction. Curr Drug Targets Cardiovasc Haematol Disord 3: 187-197, 2003.

11. Markandran K, Poh JW, Ferenczi MA and Cheung C: Regulatory light chains in cardiac development and disease. Int J Mol Sci 22: $4351,2021$.

12. Khalina YN, Bartsch H, Petzhold D, Haase H, Podlubnaya ZA, Shpagina MD and Morano I: Reconstitution of ventricular myosin with atrial light chains 1 improves its functional properties. Acta Biochim Pol 52: 443-448, 2005.

13. Zhong U, Tang K, Li H, Zhao D, Kou W, Xu S, Zhang J, Yang H, Li S, Guo R, et al: Rs4968309 in myosin light chain 4 (MYL4) associated with atrial fibrillation onset and predicts clinical outcomes after catheter ablation in atrial fibrillation patients without structural heart disease. Circ J 83: 1994-2001, 2019.

14. Arrell KK, Neverova I, Fraser H, Marbán E and Van Eyk JE: Proteomic analysis of pharmacologically preconditioned cardiomyocytes reveals novel phosphorylation of myosin light chain 1. Circ Res 89: 480-487, 2001

15. Zhang C, Wang J, Wang G, Ji Z, Hou L, Liu Z and Chao T: Molecular cloning and mRNA expression analysis of sheep MYL3 and MYL4 genes. Gene 577: 209-214, 2016.

16. Machackova J, Barta J and Dhalla NS: Myofibrillar remodelling in cardiac hypertrophy, heart failure and cardiomyopathies. Can J Cardiol 22: 953-968, 2006.

17. Petzhold D, Simsek B, Meißner R, Mahmoodzadeh S and Morano I: Distinct interactions between actin and essential myosin light chain isoforms. Biochem Biophys Res Commun 449: 284-288, 2014.

18. Ritter O, Luther HP, Haase H, Baltas LG, Baumann G, Schulte HD and Morano I: Expression of atrial myosin light chains but not $\alpha$-myosin heavy chains is correlated in vivo with increased ventricular function in patients with hypertrophic obstructive cardiomyopathy. J Mol Med (Berl) 77: 677-685, 1999.

19. Nakao K, Yasue H, Fujimoto K, Jougasaki M, Yamamoto H, Hitoshi Y, Takatsu K and Miyamoto E: Increased expression and regional differences of atrial myosin light chain 1 in human ventricles with old myocardial infarction: Analyses using two monoclonal antibodies. Circulation 86: 1727-1737, 1992. 
20. Cummins P, Price KM and Littler WA: Foetal myosin light chain in human ventricle. J Muscle Res Cell Motil 1: 357-366, 1980.

21. Sitbon YH, Yadav S, Kazmierczak K and Szczesna-Cordary D: Insights into myosin regulatory and essential light chains: A focus on their roles in cardiac and skeletal muscle function, development and disease. J Muscle Res Cell Motil 41: 313-327, 2020.

22. Gregorich ZR, Cai W, Lin Z, Chen AJ, Peng Y, Kohmoto T and Ge Y: Distinct sequences and post-translational modifications in cardiac atrial and ventricular myosin light chains revealed by top-down mass spectrometry. J Mol Cell Cardiol 107: 13-21, 2017.

23. Bil-Lula I, Lin HB, Bialy D, Wawrzyńska M, Diebel L, Sawicka J, Woźniak M and Sawicki G: Subthreshold nitric oxide synthase inhibition improves synergistic effects of subthreshold MMP-2/MLCK-mediated cardiomyocyte protection from hypoxic injury. J Cell Mol Med 20: 1086-1094, 2016.

24. Morano I: Tuning the human heart molecular motors by myosin light chairs. J Mol Med 77: 544-555, 1999.

25. Sawicki G, Leon H, Sawicka J, Sariahmetoglu M, Schulze CJ, Scott PG, Szczesna-Cordary D and Schulz R: Degradation of myosin light chain in isolated rat hearts subjected to ischemia-reperfusion injury: A new intracellular target for matrix metalloproteinase-2. Circulation 112: 544-552, 2005.

26. Kwan JA, Schulze CJ, Wang W, Leon H, Sariahmetoglu M, Sung M, Sawicka J, Sims DE, Sawicki G and Schulz R: Matrix metalloproteinase-2 (MMP-2) is present in the nucleus of cardiac myocytes and is capable of cleaving poly (ADP-ribose) polymerase (PARP) in vitro. FASEB J 18: 690-692, 2004.

27. Sariahmetoglu M, Skrzypiec-Spring M, Youssef $N$ Jacob-Ferreira AL, Sawicka J, Holmes C, Sawicki G and Schulz R: Phosphorylation status of matrix metalloproteinase 2 in myocardial ischaemia-reperfusion injury. Heart 98: 656-662, 2012.

28. Wang W, Schulze CJ, Suarez-Pinzon WL, Dyck JR, Sawicki G and Schulz R: Intracellular action of matrix metalloproteinase-2 accounts for acute myocardial ischemia and reperfusion injury. Circulation 106: 1543-1549, 2002.

29. Li Y, Fang J, Hua Y, Wang C, Mu D and Zhou K: The study of fetal rat model of intra-amniotic isoproterenol injection induced heart dysfunction and phenotypic switch of contractile proteins. Biomed Res Int 2014: 360687, 2014

30. Lin H Bin, Cadete VJJ, Sra B, Sawicka J, Chen Z, Bekar LK, Cayabyab F and Sawicki G: Inhibition of MMP-2 expression with siRNA increases baseline cardiomyocyte contractility and protects against simulated ischemic reperfusion injury. Biomed Res Int 2014: 810371, 2014

31. Tsutsui H, Kinugawa S and Matsushima S: Oxidative stress and heart failure. Am J Physiol Hear Circ Physiol 301: H2181-H2190, 2011.

32. Wang W, Sawicki G and Schulz R: Peroxynitrite-induced myocardial injury is mediated through matrix metalloproteinase-2. Cardiovasc Res 53: 165-174, 2002

33. Krzywonos-Zawadzka A, Franczak A, Olejnik A, Radomski M, Gilmer JF, Sawicki G, Woźniak M and Bil-Lula I: Cardioprotective effect of MMP-2-inhibitor-NO-donor hybrid against ischaemia/reperfusion injury. J Cell Mol Med 23: 2836-2848, 2019.

34. Nattel S: Close connections between contraction and rhythm: A new genetic cause of atrial fibrillation/cardiomyopathy and what it can teach us. Eur Heart J 38: 35-37, 2017.

35. Hernandez OM, Jones M, Guzman G and Szczesna-Cordary D Myosin essential light chain in health and disease. Am J Physiol Hear Circ Physiol 292: H1643-H1654, 2007.

36. Kopylova G, Nabiev S, Nikitina L, Shchepkin D and Bershitsky S: The properties of the actin-myosin interaction in the heart muscle depend on the isoforms of myosin but not of $\alpha$-actin. Biochem Biophys Res Commun 476: 648-653, 2016.

37. Sheehy SP, Pasqualini F, Grosberg A, Park SJ, Aratyn-Schaus Y and Parker KK: Quality metrics for stem cell-derived cardiac myocytes. Stem Cell Reports 2: 282-294, 2014.

38. Shchepkin DV, Nikitina LV, Bershitsky SY and Kopylova GV The isoforms of $\alpha$-actin and myosin affect the $\mathrm{Ca}^{2+}$ regulation of the actin-myosin interaction in the heart. Biochem Biophys Res Commun 490: 324-329, 2017.

39. Morano I and Haase H: Different actin affinities of human cardiac essential myosin light chain isoforms. FEBS Lett 408: 71-74, 1997.
40. Biały D, Wawrzyńska M, Bil-Lula I, Krzywonos-Zawadzka A Sapa-Wojciechowska A, Arkowski J, Woźniak M and Sawicki G: Low frequency electromagnetic field decreases ischemiareperfusion injury of human cardiomyocytes and supports their metabolic function. Exp Biol Med (Maywood) 243: 809-816, 2018.

41. Heussen C and Dowdle EB: Electrophoretic analysis of plasminogen activators in polyacrylamide gels containing sodium dodecyl sulfate and copolymerized substrates. Anal Biochem 102: 196-202, 1980

42. Barton PJ and Buckingham ME: The myosin alkali light chain proteins and their genes. Biochem J 231: 249-261, 1985.

43. Logvinova DS, Matyushenko AM, Nikolaeva OP, Nikolaeva OP and Levitsky DI: Transient interaction between the N-terminal extension of the essential light chain-1 and motor domain of the myosin head during the ATPase cycle. Biochem Biophys Res Commun 495: 163-167, 2018.

44. Haase H, Dobbernack G, Tünnemann G, Karczewski P, Cardoso C, Petzhold D, Schlegel WP, Lutter S, Pierschalek P, Behlke J and Morano I: Minigenes encoding N-terminal domains of human cardiac myosin light chain-1 improve heart function of transgenic rats. FASEB J 20: 865-873, 2006.

45. Sutsch G, Brunner UT, Von Schulthess C, Hirzel HO, Hess OM, Turina M, Krayenbuehl HP and Schaub MC: Hemodynamic performance and myosin light chain-1 expression of the hypertrophied left ventricle in aortic valve disease before and after valve replacement. Circ Res 70: 1035-1043, 1992.

46. Cummins P: Transitions in human atrial and ventricular myosin light-chain isoenzymes in response to cardiac-pressure-overload-induced hypertrophy. Biochem J 205: 195-204, 1982.

47. Diffee GM, Seversen EA, Stein TD and Johnson JA: Microarray expression analysis of effects of exercise training: Increase in atrial MLC-1 in rat ventricles. Am J Physiol Hear Circ Physiol 284: H830-H837, 2003.

48. Fujimoto K, Yasue H, Nakao K, Yamamoto H, Hitoshi Y, Jougasaki M, Okumura K, Ogawa H, Takatsu K and Miyamoto E: Novel monoclonal antibodies specific for human cardiac myosin light-chain 1: Useful tools for analysis of normal and pathological hearts. J Histochem Cytochem 41: 35-42, 1993

49. Schaub MC, Tuchschmid CR, Srihari T and Hirzel HO: Myosin isoenzymes in human hypertrophic hearts. Shift in atrial myosin heavy chains and in ventricular myosin light chains. Eur Heart J 5 (Suppl F): S85-S93, 1984.

50. Olejnik A, Krzywonos-Zawadzka A, Banaszkiewicz M and Bil-Lula I: Ameliorating effect of Klotho protein on rat heart during I/R injury. Oxid Med Cell Longev 2020: 6427284, 2020.

51. Cadete VJJ, Sawicka J, Jaswal JS, Lopaschuk GD, Schulz R, Szczesna-Cordary D and Sawicki G: Ischemia/reperfusion-induced myosin light chain 1 phosphorylation increases its degradation by matrix metalloproteinase 2. FEBS J 279: 2444-2454, 2012

52. Turer AT and Hill JA: Pathogenesis of myocardial ischemia-reperfusion injury and rationale for therapy. Am J Cardiol 106 360-368, 2010.

53. Bil-Lula I, Krzywonos-Zawadzka A, Sawicka J, Bialy D, Wawrzynska M, Wozniak M and Sawicki G: L-NAME improves doxycycline and ML-7 cardioprotection from oxidative stress. Front Biosci (Landmark Ed) 23: 298-309, 2018

54. Banaszkiewicz M, Krzywonos-Zawadzka A, Olejnik A and Bil-Lula I: Tissue expression of atrial and ventricular myosin light chains in the mechanism of adaptation to oxidative stress. Int J Mol Sci 21: 8384, 2020.

55. Cheung PY, Sawicki G, Wozniak M, Wang W, Radomski MW and Schulz R: Matrix metalloproteinase-2 contributes to ischemia-reperfusion injury in the heart. Circulation 101: 1833-1839, 2000

56. Ben-Yosef Y, Lahat N, Shapiro S, Bitterman H and Miller A: Regulation of endothelial matrix metalloproteinase- 2 by hypoxia/reoxygenation. Circ Res 90: 784-791, 2002.

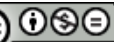

This work is licensed under a Creative Commons Attribution-NonCommercial-NoDerivatives 4.0 International (CC BY-NC-ND 4.0) License. 